\title{
Protein-Lipid Interactions with Fusobacterium nucleatum Major Outer Membrane Protein FomA: Spin-Label EPR and Polarized Infrared Spectroscopy ${ }^{\dagger}$
}

\author{
V. Anbazhagan, ${ }^{\ddagger}$ N. Vijay, ${ }^{\S}$ J. H. Kleinschmidt, ${ }^{\S}$ and D. Marsh*** \\ Max-Planck-Institut für biophysikalische Chemie, Abt. Spektroskopie, 37070 Göttingen, Germany, and University of Konstanz, \\ Fachbereich Biologie, 78457 Konstanz, Germany
}

\begin{abstract}
FomA, the major outer membrane protein of Fusobacterium nucleatum, was expressed and purified in Escherichia coli and reconstituted from detergent in bilayer membranes of phosphatidylcholines with chain lengths from $\mathrm{C}(12: 0)$ to $\mathrm{C}(17: 0)$. The conformation and orientation of membrane-incorporated FomA were determined from polarized, attenuated total reflection, infrared (IR) spectroscopy, and lipid-protein interactions with FomA were characterized by using electron paramagnetic resonance (EPR) spectroscopy of spin-labeled lipids. Approximately 190 residues of membranous FomA are estimated to be in a $\beta$-sheet configuration from IR band fitting, which is consistent with a 14-strand transmembrane $\beta$-barrel structure. IR dichroism of FomA indicates that the $\beta$-strands are tilted by $\sim 45^{\circ}$ relative to the sheet/barrel axis and that the order parameter of the latter displays a discontinuity corresponding to hydrophobic matching with fluid $\mathrm{C}(13: 0)$ lipid chains. The stoichiometry $\left(N_{\mathrm{b}}=23\right.$ lipids/monomer $)$ of lipid-protein interaction from EPR demonstrates that FomA is not trimeric in membranes of diC(14:0) phosphatidylcholine and is consistent with a monomeric $\beta$-barrel of $14-16$ strands. The pronounced selectivity of interaction found with anionic spin-labeled lipids places basic residues of the protein in the vicinity of the polar-apolar membrane interfaces, consistent with current topology models. Comparison with similar data from the 8- to 22-stranded E. coli outer membrane proteins, OmpA, OmpG, and FhuA, supports the above conclusions.
\end{abstract}

Fusobacterium nucleatum is an anaerobic Gram-negative bacterium that constitutes part of the indigenous oral microflora in humans and is among the species most frequently isolated from dental plaque. It is associated with infection of the periodontal pockets in adults and is the most common periodontal bacterium in clinical infections at other sites of the body $(1,2)$. Fusobacteria of this type are proposed to act as a bridge between early and late plaque-colonizing bacteria (3). The major protein in the outer membrane of $F$. nucleatum is FomA, which is a nonspecific porin (4) that during invasion coaggregates with the early colonizing Streptococcus sanguis and binds the later colonizing Porphorymonas gingiavalis $(5,6)$.

The FomA protein consists of a single $40 \mathrm{kDa}$ polypeptide chain of 348 residues with a high content of $\beta$-sheet $(7,8)$. The three-dimensional structure of the protein is not known, but it is thought to be a $\beta$-barrel that is composed of either $14(8)$ or $16(9)$ antiparallel strands. The oligomeric state of FomA is also a matter of debate. A trimeric structure, like that of the classical bacterial porins, has been proposed on

\footnotetext{
${ }^{\dagger}$ V.A. was supported by a fellowship from the Alexander von Humboldt Foundation and N.V. by the Marie-Curie EST program "The Biomembrane". This work was supported in part by Grant TP B3 of TR-SFB 11 of the Deutsche Forschungsgemeinschaft to J.H.K.

* To whom correspondence should be addressed. D.M.: telephone, +49 551 1285; fax, +49 551 1501; e-mail, dmarsh@gwdg.de. J.H.K.: telephone, +49 753188 2291; e-mail, joerg.helmut.kleinschmidt@ uni-konstanz.de.

¥ Max-Planck-Institut für biophysikalische Chemie.

${ }^{\S}$ University of Konstanz.
}

the basis of ion conductance measurements (4). On the other hand, FomA in its undenatured form migrates as a compact monomer on SDS-PAGE ${ }^{1}$ and incorporates spontaneously into lipid vesicles from urea with pseudo-first-order kinetics (10).

For the present study, FomA is reconstituted into lipid membranes of different hydrophobic thicknesses (cf. ref 11). The orientation and conformation of the protein in the membrane are determined with polarized IR spectroscopy $(12,13)$, and the protein-lipid interactions of FomA are characterized by using EPR spectroscopy of spin-labeled lipids $(14,15)$. In previous work with monomeric $\beta$-barrel proteins from Escherichia coli, we determined the stoichiometry and selectivity of lipid-protein interactions with the eightstranded outer membrane protein OmpA, with the 14stranded diffusion pore OmpG, and with the 22-stranded ferrichrome-iron receptor FhuA and investigated the incorporation of these proteins into membranes of different thicknesses by using polarized ATR spectroscopy (16-18).

\footnotetext{
${ }^{1}$ Abbreviations: EPR, electron paramagnetic resonance; 14-PCSL, -PASL, -PGSL, -PESL, and -PSSL, 1-acyl-2-[14-(4,4-dimethyloxazolidinyl- $N$-oxyl)]stearoyl-sn-glycero-3-phosphocholine, -phosphoric acid, -phosphoglycerol, -phosphoethanolamine, and -phosphoserine, respectively; 14-DGSL, 1-acyl-2-[14-(4,4-dimethyloxazolidinyl- $N$-oxyl)]stearoyl$s n$-glycerol; 14-SASL, 14-(4,4-dimethyloxazolidinyl- $N$-oxyl)stearic acid; PtdCho, phosphatidylcholine; ATR, attenuated total reflectance; FTIR, Fourier transform infrared; IPTG, isopropyl $\beta$-D-thiogalactopyranoside; Tris, tris(hydroxymethyl)aminomethane; Hepes, $N$-(2-hydroxyethyl)piperazine- $N^{\prime}$-2-ethanesulfonic acid; EDTA, ethylenediaminetetraacetic acid; OBG, $n$-octyl $\beta$-D-glucopyranoside; SDS-PAGE, polyacrylamide gel electrophoresis in sodium dodecyl sulfate.
} 
Scheme 1: Chemical Structures of Spin-Labeled Lipids

(14)

Comparison with these previously published data on proteins of known structure is used to obtain information about the $\beta$-barrel architecture of FomA and its state of oligomerization when incorporated into lipid bilayer membranes.

\section{MATERIALS AND METHODS}

Materials. Chemical structures of the spin-labeled lipids used are given in Scheme 1. Spin-labeled stearic acid, 14SASL, was synthesized according to refs 15 and 19. Spinlabeled phosphatidylcholine, 14-PCSL, was synthesized by acylation of lysophosphatidylcholine with 14-SASL, as described in refs 15 and 20. Other spin-labeled phospholipids, 14-PGSL, 14-PESL, 14-PSSL, and 14-PASL, were prepared from 14-PCSL by headgroup exchange mediated by phospholipase D $(15,20)$. Spin-labeled diacylglycerol, 14-DGSL, was synthesized from 14-PCSL by the action of phospholipase $\mathrm{C}$, as described in ref 21 . Symmetrical, disaturated phosphatidylcholines, $\operatorname{diC}\left(n_{\mathrm{C}}: 0\right) \mathrm{PtdCho}$, with odd and even chain lengths from 12 to 17 were obtained from Avanti Polar Lipids (Alabaster, AL). All other chemicals were from Sigma Chemical Co. (St. Louis, MO).

Isolation of FomA. FomA was expressed in the form of cytoplasmic inclusion bodies in E. coli B strain PC2889 harboring the pET-10953 plasmid, as described by Pocanschi et al. (10). Briefly, to express FomA, 0.1 M IPTG was added to a PC2889 culture at an $A_{660}$ of 0.6 . After $2-3 \mathrm{~h}$, cells were harvested at $4{ }^{\circ} \mathrm{C}$ by centrifugation and resuspended in Tris buffer. Cells were disrupted with a Branson model W-450 D ultrasonifer to produce inclusion bodies of FomA, which were resuspended in $10 \mathrm{mM}$ borate buffer ( $\mathrm{pH} 10)$ containing $8 \mathrm{M}$ urea. The solubilized protein was loaded onto a DEAE-Sephadex column which was pre-equilibrated with borate buffer. Unfolded FomA was eluted with an $\mathrm{NaCl}$ gradient from 0 to $200 \mathrm{mM}$ with a flow rate of $2 \mathrm{~mL} / \mathrm{min}$. Folding of FomA was initiated by rapidly mixing the denatured FomA with a 60 -fold larger volume of $10 \mathrm{mM}$ borate, 2 mM EDTA buffer that contained $1 \% n$-octyl $\beta$-Dglucopyranoside (OBG) detergent micelles. Refolding was monitored by SDS-PAGE, taking advantage of the difference in migration of refolded (37 kDa) and unfolded (40 $\mathrm{kDa}$ FomA, when samples are not boiled prior to electrophoresis. Protein concentrations were determined by the method of Lowry et al. (22), using $1 \mathrm{mg} / \mathrm{mL}$ bovine serum albumin (Sigma Chemical Co.) as a standard.

Reconstitution of FomA into Membranes. Phospholipid solutions containing the desired spin-labeled lipid at $1 \mathrm{~mol}$ $\%$ were prepared in $\mathrm{CHCl}_{3}$ and dried under a stream of dry nitrogen gas. The resulting lipid film was desiccated overnight under vacuum and then covered with argon. The dry lipid film was hydrated with $10 \mathrm{mM}$ borate buffer containing 2 mM EDTA and $1 \%$ OBG micelles, at pH 10. Reconstitution was carried out by mixing $1 \mathrm{mg}$ of the detergentsolubilized lipid vesicles with FomA to the desired lipid: protein ratio. The sample was mixed well and incubated overnight at $37{ }^{\circ} \mathrm{C}$. Detergent removal was achieved by extensive dialysis at $8{ }^{\circ} \mathrm{C}$ against $10 \mathrm{mM}$ Hepes buffer $(\mathrm{pH}$ 7.4) containing $2 \mathrm{mM}$ EDTA, using $10 \mathrm{kDa}$ cutoff dialysis membranes. Six to eight changes of $2 \mathrm{~L}$ of buffer were made every $7-8 \mathrm{~h}$, with a last dialysis step overnight.

ATR Spectroscopy. Polarized ATR infrared spectra were recorded on a Bruker IFS 25 FTIR spectrometer at a nominal resolution of $2 \mathrm{~cm}^{-1}$, with parallel and perpendicular polarization of the incident beam. A reconstituted FomA/ membrane sample with a lipid:protein molar ratio of $\sim 50$ was layered on a clean ZnSe ATR crystal. Initially, the sample was dried with dry nitrogen purge and then desiccated overnight with a vacuum pump. The sample was rehydrated with $10 \mathrm{mM}$ Hepes buffer in $\mathrm{D}_{2} \mathrm{O}$ (pD 7.4) containing $2 \mathrm{mM}$ EDTA and then washed (using a pipet) with the same buffer to remove noninserted lipid and protein. Meanwhile, ATR spectra were recorded at both polarizations for every wash. The sample holder was temperature controlled using a recirculating water bath, and the spectra were recorded in the gel phase $\left(\sim 10^{\circ}\right.$ below the lipid chain-melting temperature) and in the fluid phase $\left(\sim 10^{\circ}\right.$ above the lipid chainmelting temperature) of the bilayer membranes. Further details of the ATR spectroscopy are given in refs 18 and 23.

To determine the dichroic ratios, each spectrum was analyzed using the Peak Fitting Module of Origin Pro 7 (Microcal Software, Hampton, MA). If necessary, spectra were smoothed with an 11-point Savitsky-Golay filter to remove the noise from residual water vapor. A local baseline was established, and curve fitting using nonlinear leastsquares minimization with Lorentzian components was carried out from 1500 to $1710 \mathrm{~cm}^{-1}$ and from 1590 to 1690 $\mathrm{cm}^{-1}$ for dry and hydrated samples, respectively (except that a Gaussian component was used for the major $1623 \mathrm{~cm}^{-1}$ component of the latter). The $\mathrm{CH}$ stretching bands, in the region from 2830 to $2975 \mathrm{~cm}^{-1}$, were fitted similarly. Absorption intensities for parallel and perpendicularly polarized radiation were obtained from the curve fitting analysis of the amide I and amide II bands at 1628 and $1530 \mathrm{~cm}^{-1}$, respectively, and of the symmetric and asymmetric $\mathrm{CH}$ stretch bands at 2850 and $2920 \mathrm{~cm}^{-1}$, respectively. The ratios of the parallel and perpendicular absorption intensities define the ATR dichroic ratios $(R)$ at these wavelengths. Fitting the major component of the dry sample at $1628 \mathrm{~cm}^{-1}$ with 


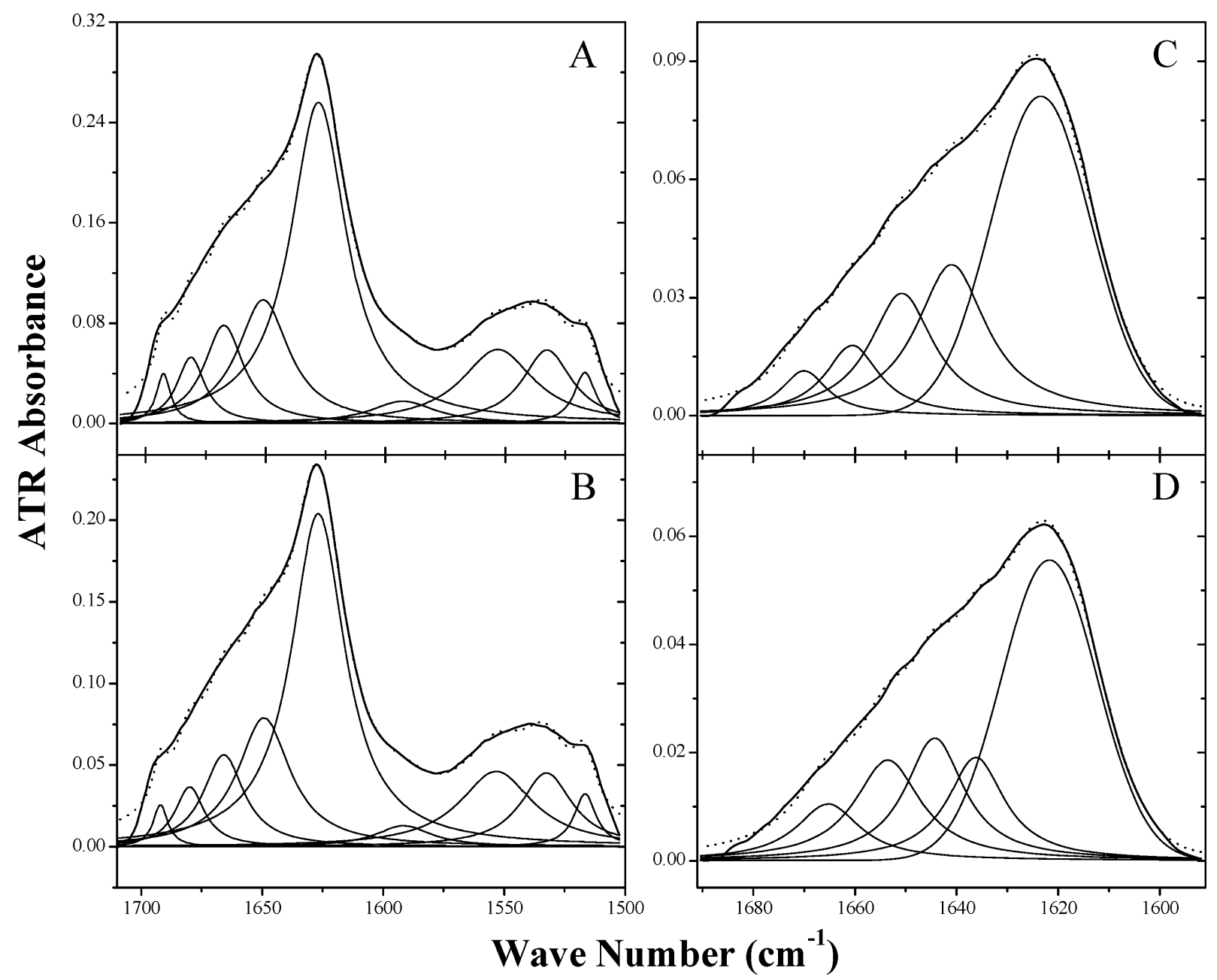

FIGURE 1: Polarized ATR-IR spectra of FomA reconstituted in lipid bilayers of ditridecanoyl phosphatidylcholine (diC(13:0)PtdCho). Spectra $\mathrm{A}$ and $\mathrm{B}$ are obtained in the dry state, whereas spectra $\mathrm{C}$ and $\mathrm{D}$ are obtained in the hydrated fluid phase. The spectra in the upper panels (A, C) correspond to parallel polarization, and those in the lower panels (B,D) correspond to perpendicular polarization, of the incident radiation. Note the different ordinate scales. The dotted lines correspond to the least-squares fit, with the bands obtained from the bandfitting analysis shown below the experimental spectrum. The positions and widths at half-height of the major amide I band are: A) 1628 $\mathrm{cm}^{-1}$ and $28 \mathrm{~cm}^{-1}$ (Lorentzian); B) $1627 \mathrm{~cm}^{-1}$ and $27 \mathrm{~cm}^{-1}$ (Lorentzian); C) $1623 \mathrm{~cm}^{-1}$ and $23 \mathrm{~cm}^{-1}$ (Gaussian); D) $1622 \mathrm{~cm}^{-1}$ and 22 $\mathrm{cm}^{-1}$ (Gaussian).

a Gaussian, instead of a Lorentzian, band shape had a negligible effect on the dichroic ratio calculated. The measured dichroic ratio changes with the first two to three washes and then becomes stable, which is taken to correspond to the aligned hydrated samples. To calculate molecular orientations from dichroic ratios, intensities of the infrared electric field components were obtained from the thick-film approximation: $E_{x}{ }^{2} / E_{y}{ }^{2}=0.450$ and $E_{z}{ }^{2} / E_{y}{ }^{2}=$ 1.550 for a $45^{\circ}$-cut ZnSe ATR crystal (13).

Electron Paramagnetic Resonance Spectroscopy. EPR spectra were recorded on a $9 \mathrm{GHz}$ Bruker EMX EPR spectrometer equipped with a model ER 041 XK-D microwave bridge. Samples were placed in $50 \mu \mathrm{L}$ glass capillaries and flame-sealed. The capillaries were placed in a standard $4 \mathrm{~mm}$ quartz sample tube containing light silicone oil for thermal stability. The temperature of the sample was kept constant by blowing thermostated nitrogen gas through a quartz Dewar. Spectra were recorded using the following instrumental settings: sweep width, $100 \mathrm{G}$; resolution, 1024 points; time constant, $20.5 \mathrm{~ms}$; sweep time, $42 \mathrm{~s}$; modulation frequency, $100 \mathrm{kHz}$; modulation amplitude, $1.0 \mathrm{G}$; incident power, $5 \mathrm{~mW}$. Spectral subtraction or addition and integration were performed as described in refs 15 and 24. Spectral reference libraries for the fluid and motionally restricted components were obtained from 14-PCSL in egg PtdCho dispersions and in sonicated diC(14:0)PtdCho small unilamellar vesicles, respectively, at various temperatures.

\section{RESULTS}

Polarized IR Spectra of FomA in PtdCho. Figure 1 shows the amide region from the polarized ATR spectra of FomA in aligned membranes of ditridecanoylphosphatidylcholine [diC(13:0)PtdCho]. In the dry state (Figures 1A,B), both the amide I and amide II bands are visible, whereas in membranes hydrated with $\mathrm{D}_{2} \mathrm{O}$ (Figures 1C,D), the amide II band is shifted by $\sim 100 \mathrm{~cm}^{-1}$ to lower frequencies where it overlaps with bands from the lipid. Qualitatively, the band shapes resemble those of known $\beta$-barrel outer membrane proteins in the dry and hydrated states (see, e.g., refs 17 and 18). Band fitting shown in Figure 1 demonstrates the predominant $\beta$-sheet content of FomA, with the major band at ca. $1625 \mathrm{~cm}^{-1}$ in the amide I region $\left[\nu_{\perp}(\pi, 0)\right.$ mode] and at ca. $1530-1550 \mathrm{~cm}^{-1}$ in the amide II region $\left[\nu_{\|}(0, \pi)\right.$ mode]. The minor band at ca. $1670-90 \mathrm{~cm}^{-1}$ in the amide I region 
Table 1: Band Fitting of the Polarized ATR Spectra from the Amide I Band of FomA in Hydrated Disaturated Phosphatidylcholines, $\operatorname{diC}\left(n_{\mathrm{C}}: 0\right) P t d C h o$, with Different Chain Lengths, $n_{\mathrm{C}}$, in the Gel and Fluid Phases

\begin{tabular}{lccccc}
\hline & \multicolumn{2}{c}{ gel } & & \multicolumn{2}{c}{ fluid } \\
\cline { 2 - 3 } \cline { 5 - 5 } $\mathrm{C}\left(n_{\mathrm{C}}: 0\right)$ & $\begin{array}{c}\text { position } \\
\left(\mathrm{cm}^{-1}\right)\end{array}$ & $\begin{array}{c}\text { normalized } \\
\text { area }(\%)^{a}\end{array}$ & & $\begin{array}{c}\text { position } \\
\left(\mathrm{cm}^{-1}\right)\end{array}$ & $\begin{array}{c}\text { normalized } \\
\text { area }(\%)^{a}\end{array}$ \\
\hline $\mathrm{C}(12: 0)$ & & & 1623 & 54 \\
& & & & 1641 & 17 \\
& & & & 1649 & 14 \\
& & & 1659 & 10 \\
$\mathrm{C}(14: 0)$ & 1623 & 52 & 1669 & 5 \\
& 1639 & 15 & 1641 & 51 \\
& 1648 & 15 & 1650 & 20 \\
& 1658 & 12 & 1660 & 8 \\
$\mathrm{C}(16: 0)$ & 1668 & 6 & 1670 & 4 \\
& 1620 & 44 & & 1620 & 44 \\
& 1635 & 19 & 1635 & 19 \\
& 1644 & 14 & 1644 & 13 \\
& 1653 & 14 & 1653 & 13 \\
& 1666 & 9 & 1665 & 11 \\
\hline
\end{tabular}

${ }^{a}$ Relative band intensities were obtained by combining integrated absorbances, $A_{\|}$and $A_{\perp}$, with radiation polarized parallel and perpendicular, respectively, to the plane of the incident beam. The appropriate combination that reflects the full intensity is $A_{\|}+\left(2 E_{z}^{2} / E_{y}^{2}\right.$ $\left.-E_{x}^{2} / E_{y}^{2}\right) A_{\perp}(64)$.

$\left[\nu_{\|}(0, \pi)\right.$ mode $]$ from dry and hydrated membranes is characteristic of antiparallel $\beta$-sheets (25).

Table 1 gives the results of band fitting for the amide I region from FomA in selected disaturated phosphatidylcholines of different chain lengths. Data for the complete set of phosphatidylcholine chain lengths, odd and even, from diC(12:0)PtdCho to diC(17:0)PtdCho are given in Table S1 of the Supporting Information. Fitting data are given for hydrated membranes in the gel and fluid phases, recorded at temperatures $10^{\circ}$ below and $10^{\circ}$ above the respective chainmelting transitions (see ref 26 ). The conformational populations are very similar in the fluid and gel phases of a given lipid, as would be expected for the $\beta$-barrel domain of a protein. The $\beta$-sheet population of FomA is in the region of $55-60 \%$ for phosphatidylcholine host lipids with chain lengths in the range from $\mathrm{C}(12: 0)$ to $\mathrm{C}(16: 0)$, with a lower value of $46 \%$ in $\operatorname{diC}(17: 0) \operatorname{PtdCho}$. The mean $\beta$-sheet content of FomA, over the entire range of lipids, is $55 \pm 5 \%$.

Amide Dichroism of FomA in PtdCho. Figure 2 gives the dichroic ratios of the amide I band from FomA in bilayer membranes hydrated in $\mathrm{D}_{2} \mathrm{O}$, as a function of chain length, $n_{\mathrm{C}}$, of the disaturated PtdCho. Values are given for membranes in the gel phase and for those in the fluid phase, above the lipid chain melting temperature. The general trend is an increase in amide I dichroic ratio with increasing lipid chain length, and mostly larger values in the fluid phase than in the gel phase.

A single dichroic ratio is insufficient to define the orientation of a $\beta$-sheet membrane protein, because this depends both on the tilt, $\beta$, of the strands within the sheet and on the inclination, $\alpha$, of the sheet to the membrane normal (see ref 12 and the left panel of Figure 7). For a $\beta$-barrel of large radius (or a flattened barrel), the dichroism can be approximated by that for a planar sheet. The dichroic ratio of the amide I band is then given by (12)

$$
R_{\mathrm{I}}=\frac{2\left\langle\cos ^{2} \alpha\right\rangle\left\langle\sin ^{2} \beta\right\rangle}{1-\left\langle\cos ^{2} \alpha\right\rangle\left\langle\sin ^{2} \beta\right\rangle} \frac{E_{z}^{2}}{E_{y}^{2}}+\frac{E_{x}^{2}}{E_{y}^{2}}
$$

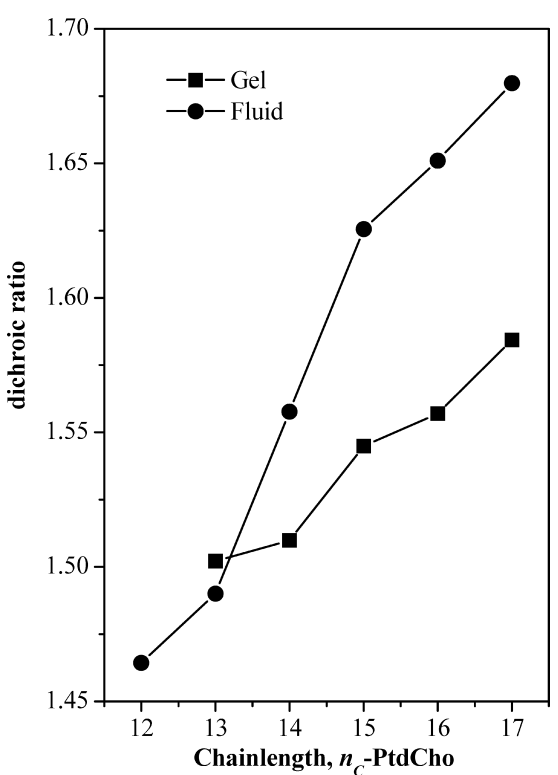

FIGURE 2: Dependence of the dichroic ratios from the amide I band of FomA on the lipid chain length, $n_{\mathrm{C}}$, of the $\operatorname{diC}\left(n_{\mathrm{C}}: 0\right) \operatorname{PtdCho}$ membrane in which the protein is incorporated. Dichroic ratios are given for samples in the gel phase ( $\mathbf{\square})$ and in the fluid phase (0). Membranes are hydrated in excess $\mathrm{D}_{2} \mathrm{O}$ buffer.

because the transition moment of the $v_{\perp}(\pi, 0)$ mode is oriented perpendicular to the strand axis. On the other hand, the transition moment of the $v_{\|}(0, \pi)$ mode for the amide II band is directed along the strand axis, and the dichroic ratio is given by

$$
R_{\mathrm{II}}=\frac{2\left\langle\cos ^{2} \alpha\right\rangle\left\langle\cos ^{2} \beta\right\rangle}{1-\left\langle\cos ^{2} \alpha\right\rangle\left\langle\cos ^{2} \beta\right\rangle} \frac{E_{z}^{2}}{E_{y}^{2}}+\frac{E_{x}^{2}}{E_{y}^{2}}
$$

where angular brackets indicate an ensemble average. Combining dichroic ratios from the amide I and amide II bands therefore allows determination of $\left\langle\cos ^{2} \alpha\right\rangle$ and $\left\langle\cos ^{2} \beta\right\rangle$ separately. Applying this to the dichroic ratios, $R_{\mathrm{I}}$ and $R_{\mathrm{II}}$, of the dry samples yields a consistent mean value for the strand tilt $(\beta)$ of $44.8 \pm 0.5^{\circ}(N=11)$ from measurements on FomA in $\operatorname{diC}\left(n_{\mathrm{C}}: 0\right)$ PtdCho with chain lengths from 12 to 17 .

Using this mean value of the strand tilt $\left(\beta=45^{\circ}\right)$, deduced from the dry sample, together with the dichroic ratios of the amide I band for the hydrated samples from Figure 2, yields the values for the order parameter, $\left\langle P_{2}(\cos \alpha)\right\rangle$, and effective mean tilt, $\alpha$, of the $\beta$-sheets that are given in Figure 3 (top and middle, respectively). The trend is similar to that of the dichroic ratios: the order parameters increase, and the tilt angles decrease, with increasing lipid chain length.

Lipid Chain Dichroism in FomA/PtdCho. The effective tilt angles, $\theta_{\mathrm{ch}}$, of the lipid chains, relative to the substrate normal, are given in Figure 3 (bottom). These values are derived from the dichroic ratios, $R_{\mathrm{CH}_{2}}$, of the $\mathrm{CH}_{2}$ symmetric and antisymmetric stretch bands at 2850 and $2920 \mathrm{~cm}^{-1}$, respectively. The transition moment for $\mathrm{CH}_{2}$ stretch vibrations is perpendicular to the chain axis, and the dichroic ratio is given by (see, e.g., ref 13)

$$
R_{\mathrm{CH}_{2}}=2 \frac{1-\left\langle\cos ^{2} \theta_{\mathrm{ch}}\right\rangle}{1+\left\langle\cos ^{2} \theta_{\mathrm{ch}}\right\rangle} \frac{E_{z}^{2}}{E_{y}^{2}}+\frac{E_{x}^{2}}{E_{y}^{2}}
$$

Consistent values for $\theta_{\text {ch }}$ are obtained from the symmetric and antisymmetric stretch bands. In the gel phase, the values 


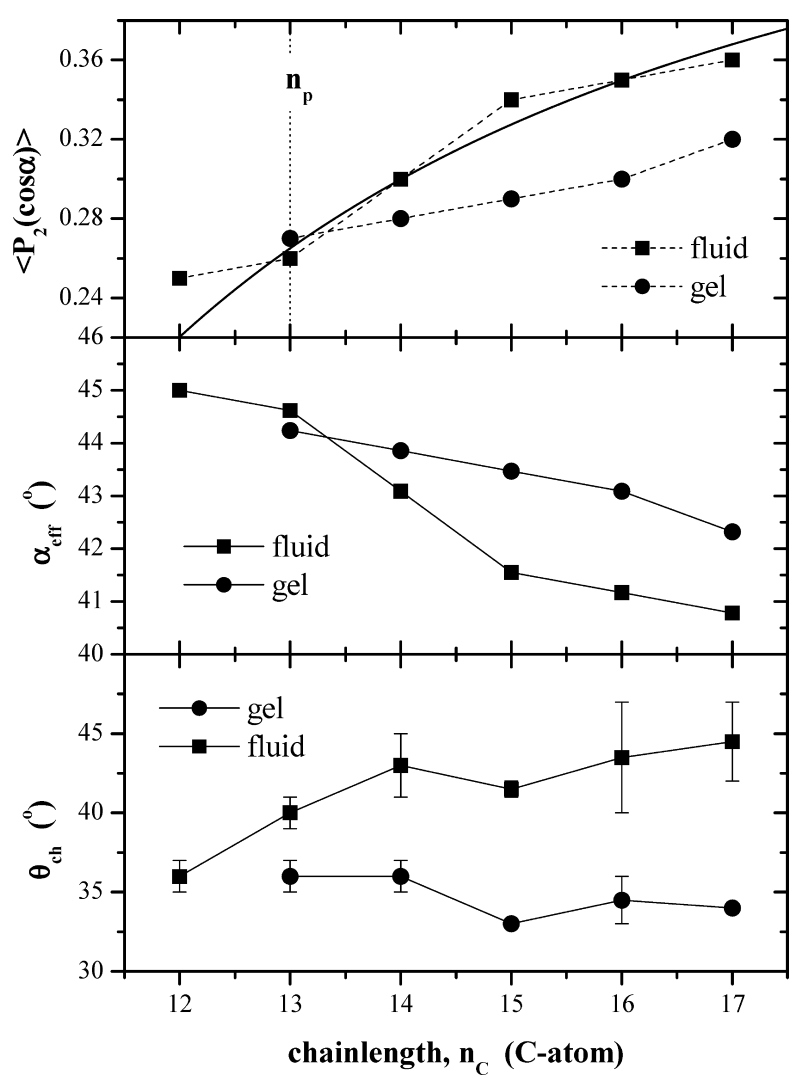

FIGURE 3: Dependence of the order parameters $\left\langle P_{2}(\cos \alpha)\right\rangle$ (top panel) and mean effective inclinations $\alpha_{\text {eff }}$ (middle panel) of FomA on the lipid chain length, $n_{\mathrm{C}}$, of the gel-phase (-) or fluid-phase (ם) $\operatorname{diC}\left(n_{\mathrm{C}}: 0\right)$ PtdCho membrane in which FomA is incorporated. In the top panel, the vertical dashed line corresponds to the lipid chain length, $n_{\mathrm{P}}$, that gives hydrophobic matching with outer membrane proteins; the solid line is a nonlinear least-squares fit of the chain length dependence $\left\{P_{2} \sim\left[1-B /\left(n_{\mathrm{C}}-1\right)^{2}\right] \times f\right.$ (where $\left.\left.n_{\mathrm{C}} \geq n_{\mathrm{P}}\right)\right\}$ that is expected for elastic bending fluctuations of the membrane (50). In the bottom panel are given the effective tilt angles, $\theta_{\mathrm{ch}}$, of the lipid chains of the FomA-containing membranes in the gel (-) and fluid (ם) phases. Values are the means of determinations from the $\mathrm{CH}_{2}$ symmetric and antisymmetric stretch bands at 2850 and $2920 \mathrm{~cm}^{-1}$, respectively.

of $\theta_{\mathrm{ch}}$ correspond to the tilt of the long axis of the nearly all-trans chains. In the fluid phase, $\theta_{\mathrm{ch}}$ is larger, corresponding to chain fluidization; it is then only an effective value that represents the mean order parameter of the individual chain segments that are undergoing rotational isomerism. For comparison, the static tilt of the chains of disaturated phosphatidylcholines in gel-phase bilayers that is determined from X-ray diffraction lies in the range of $30-35^{\circ}(26)$. The values of $\theta_{\text {ch }}$ that are presented for the gel-phase membranes in Figure 3 are close to this range and therefore indicate that the reconstituted membranes which contain FomA are reasonably well aligned.

EPR of Spin-Labeled Phosphatidylcholine. Figure 4 shows the EPR spectra of spin-labeled phosphatidylcholine, 14PCSL, in bilayers of diC(14:0)PtdCho that contain FomA reconstituted at different lipid/protein ratios, as indicated. The spectra were recorded at $30{ }^{\circ} \mathrm{C}$, i.e., in the fluid phase of diC(14:0)PtdCho lipid bilayers. With the exception of the lowest lipid:protein ratio, the EPR spectra in Figure 4 all consist of two components. The sharper spectral component is characteristic of lipids in fluid bilayer regions of the membrane, and the broader component is characteristic of lipids that are motionally restricted at the intramembrane

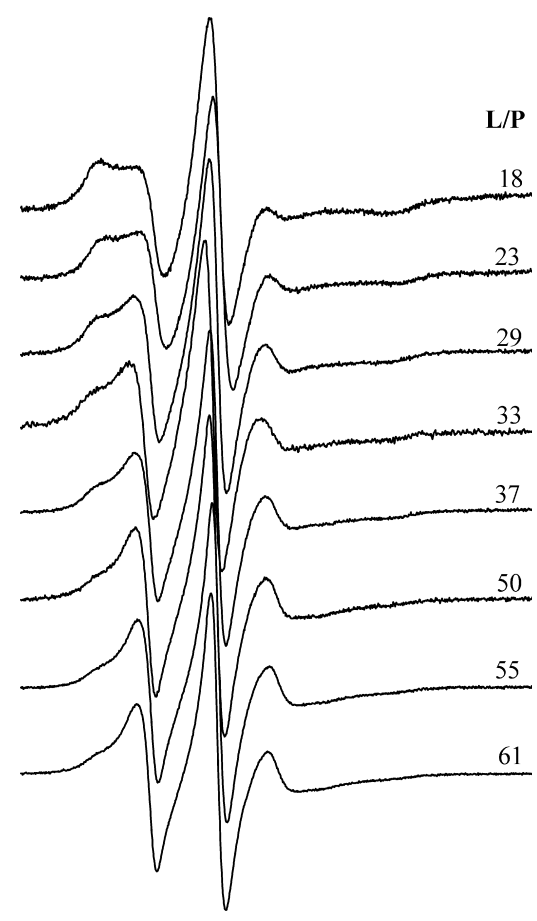

FIGURE 4: EPR spectra of phosphatidylcholine spin-labeled on the C14 atom of the $s n-2$ chain (14-PCSL) in diC(14:0)PtdCho membranes containing FomA at the lipid:protein molar ratios indicated in the figure. $T=30{ }^{\circ} \mathrm{C}$; total scan width $=100 \mathrm{G}$.

surface of FomA (see, e.g., refs 27-30). Detection of this motionally restricted lipid population indicates that FomA is integrated in the lipid bilayer in a transmembrane fashion (cf. refs 14 and 31 ).

Detailed temperature scans were performed, over the range from 0 to $40{ }^{\circ} \mathrm{C}$, to check that membranes containing FomA were in the fluid phase at $30^{\circ} \mathrm{C}$. Figure S1 of the Supporting Information gives chain melting (i.e., gel-fluid) phase transition curves for $\mathrm{diC}(14: 0)$ PtdCho bilayers in the presence and absence of 1:36 mol/mol of FomA, which are registered by recording the central spin-label EPR line height, normalized to the second integral of the conventional first-derivative spectrum. These show that the transition is broadened mostly on the lowtemperature side and confirm that $\mathrm{FomA} / \mathrm{diC}(14: 0) \mathrm{PtdCho}$ membranes are still in the fluid phase at $30^{\circ} \mathrm{C}$, at protein:lipid molar ratios of up to 1:36.

Spectral subtraction and addition were used to demonstrate the two-component nature of the lipid EPR spectra from FomA-containing membranes. Figure S2 of the Supporting Information shows how the spectrum of 14-PCSL in FomA/ $\operatorname{diC}(14: 0) P t d C h o ~ 1: 33 \mathrm{~mol} / \mathrm{mol}$ membranes is analyzed by using spectral subtraction or addition to yield the relative proportions of the two spin-labeled lipid populations. A subtraction end point that yields the spectral component arising only from the motionally restricted lipids (Figure S2B) reveals that $1-f_{\mathrm{b}}=29 \%$ of the total intensity must be removed from the original spectrum (Figure S2A) by using a single fluid component to subtract. Correspondingly, the complementary subtraction (Figure S2C) requires removal of $f_{\mathrm{b}}=71 \%$ of the total intensity by using a motionally restricted single component with which to subtract.

Figure 5 shows the results of analyzing the spectral data in Figure 4 by spectral addition (see the dotted line in Figure S2A), using least-squares minimization of differences from the original experimental spectrum. The ratio of fluid to 


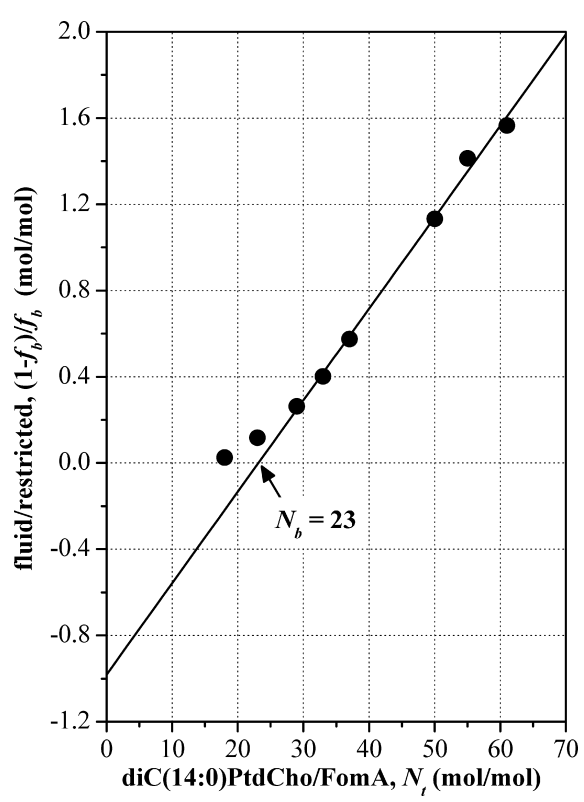

FIGURE 5: Dependence of the ratio of fluid to motionally restricted populations, $\left(1-f_{\mathrm{b}}\right) / f_{\mathrm{b}}$, of the 14-PCSL spin-label on the lipid: protein ratio, $N_{\mathrm{t}}$, in diC(14:0)PtdCho membranes containing FomA (๑). The solid line is a linear regression.

motionally restricted lipid populations, $\left(1-f_{\mathrm{b}}\right) / f_{\mathrm{b}}$, is plotted as a function of the total lipid:protein ratio, $N_{\mathrm{t}}$. According to the standard expression for equilibrium exchange association of spin-labeled lipids with the protein, the dependence on lipid:protein ratio is given by (32)

$$
\left(1-f_{\mathrm{b}}\right) / f_{\mathrm{b}}=\left(N_{\mathrm{t}} / N_{\mathrm{b}}-1\right) / K_{\mathrm{r}}
$$

at probe concentrations of spin-label, where $N_{\mathrm{b}}$ is the number of lipid association sites at the intramembranous surface of the protein and $K_{\mathrm{r}}$ is the association constant of the spinlabeled 14-PCSL lipid relative to the unlabeled diC(14:0)PtdCho host lipid. The linear regression in Figure 5, according to eq 4 , indicates a fixed stoichiometry $\left(N_{\mathrm{b}}\right)$ of 23 \pm 1 lipid sites at the intramembranous surface of FomA and an association constant of spin-labeled phosphatidylcholine relative to diC(14:0)PtdCho of $K_{\mathrm{r}}=1.0$. The latter result is consistent with findings for both $\alpha$-helical and $\beta$-barrel proteins reconstituted in $\mathrm{diC}(14: 0)$ PtdCho or other phosphatidylcholines (18, 33-36).

EPR of Different Spin-Labeled Lipid Species. Figure 6 shows the EPR spectra of different spin-labeled lipid species in FomA/diC(14:0)PtdCho membranes with identical lipid: protein ratios. The differences between the two-component spectra from the various lipid species indicate the selectivities of the different lipid polar headgroups for interaction with FomA. For a fixed lipid:protein ratio, $N_{\mathrm{t}}$, the ratio of relative association constants is given (from eq 4) by

$$
K_{\mathrm{r}} / K_{\mathrm{r}}^{\mathrm{PC}}=\left(1 / f_{\mathrm{b}}^{\mathrm{PC}}-1\right) /\left(1 / f_{\mathrm{b}}-1\right)
$$

where $f_{\mathrm{b}}^{\mathrm{PC}}$ is the fraction of motionally restricted, spin-labeled phosphatidylcholine and $f_{\mathrm{b}}$ that of the lipid in question. Values of the selectivity ratio, $K_{\mathrm{r}} / K_{\mathrm{r}}^{\mathrm{PC}}$, for the different lipids that are obtained from the data of Figure 6 by using eq 5 are given in Table 2. With the exception of phosphatidylglycerol (14-PGSL), the anionic lipids tested have relative association constants that are considerably larger than that of phosphatidylcholine (14-PCSL), implying an interaction

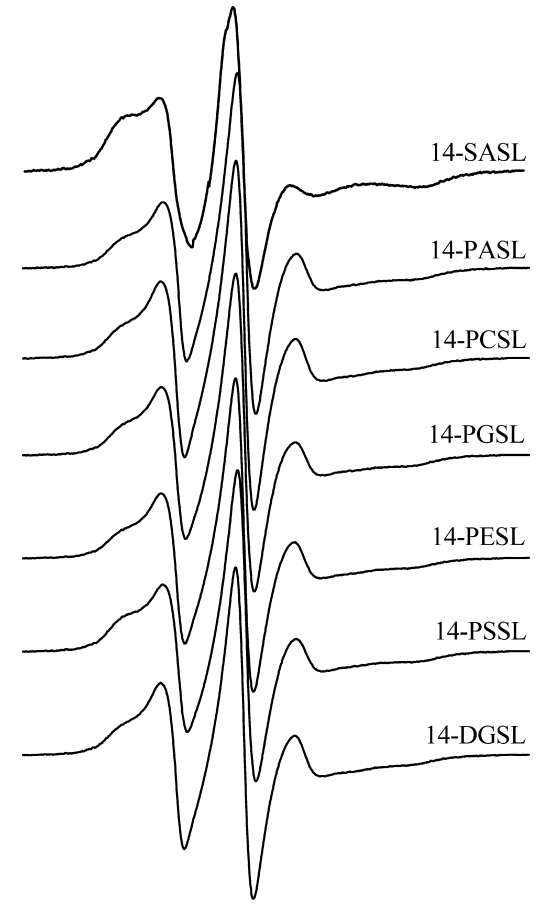

FIGURE 6: ESR spectra of spin-labeled phospholipids (14-PXSL) with different polar headgroups and of the corresponding spinlabeled diacylglycerol (14-DGSL) and stearic acid (14-SASL), in diC(14:0)PtdCho membranes containing FomA at a fixed lipid: protein molar ratio of $36: 1 . T=30{ }^{\circ} \mathrm{C}$; total scan width $=100 \mathrm{G}$.

Table 2: Fraction $\left(f_{\mathrm{b}}\right)$ of Motionally Restricted Spin-Labeled Lipid and Relative Association Constants, $K_{\mathrm{r}}$, Normalized to That for Phosphatidylcholine $\left(K_{\mathrm{r}}^{\mathrm{PC}}\right)$, Obtained by Spectral Addition for the EPR Spectra of Different Spin-Labeled Lipid Species in diC(14:0)PtdCho/ FomA Membranes at a Fixed Lipid:Protein Molar Ratio of 36:1

\begin{tabular}{lccc}
\hline $\begin{array}{c}\text { lipid } \\
\text { spin-label }\end{array}$ & $\begin{array}{c}\text { motionally restricted } \\
\text { fraction }\left(f_{\mathrm{b}}\right)\end{array}$ & $K_{\mathrm{r}} / K_{\mathrm{r}}^{\mathrm{PC}}$ & $\begin{array}{c}\Delta G-\Delta G^{\mathrm{PC}} \\
(\mathrm{kJ} / \mathrm{mol})^{a}\end{array}$ \\
\hline 14-SASL & 0.89 & 4.1 & -3.6 \\
14-PASL & 0.70 & 1.2 & -0.5 \\
14-PGSL & 0.68 & 1.1 & -0.3 \\
14-PESL & 0.67 & 1.1 & -0.2 \\
14-PSSL & 0.75 & 1.6 & -1.2 \\
14-DGSL & 0.65 & 1.0 & +0.1 \\
\hline
\end{tabular}

${ }^{a}$ Free energy of association, relative to 14-PCSL: $\Delta G-\Delta G^{\mathrm{PC}}=$ $-R T \ln \left(K_{\mathrm{r}} / K_{\mathrm{r}}^{\mathrm{PC}}\right) \cdot T=30^{\circ} \mathrm{C}$.

with basic residues at the membrane surface (see, e.g., refs 16 and $36-39)$.

\section{DISCUSSION}

Secondary Structure of Membranous FomA. The overall IR band shape of FomA in lipid membranes resembles those of outer membrane proteins from Gram-negative bacteria that are known from X-ray diffraction to have $\beta$-barrel structures. IR band analysis reveals that FomA is composed of $55 \pm 5 \%$ $\beta$-sheet and ca. $12 \pm 3 \% \alpha$-helix, in fully hydrated membranes (see Tables 1 and S1). The remainder (ca. $33 \pm 8 \%$ ) consists of turns and unordered structures. For comparison, a $\beta$-strand content of $43 \%$ and an $\alpha$-helix content of $4 \%$ were estimated from circular dichroism spectra of FomA in detergent and in small sonicated vesicles of $\mathrm{diC}(10: 0)$ PtdCho or diC(18:1)PtdCho (10). It is possible that part of the high-frequency amide I band that is attributed to the minor $v_{\|}(0, \pi)$ mode of antiparallel $\beta$-sheets in the present estimate from IR spectra may be 
contributed by $\beta$-turns (40). If this is the case, the minimum estimate for $\beta$-sheet content from IR spectroscopy is given by the major $1623 \mathrm{~cm}^{-1}$ band alone in Tables 1 and $\mathrm{S} 1$, which lies in the range of $37-57 \%$ with a mean value of $49 \pm 7 \%$. Any residual discrepancy between estimates from the two methods could indicate that FomA is less structured in detergent or sonicated vesicles than in extended bilayer membranes and may also reflect the known difficulties in analyzing proteins with high $\beta$-sheet content by circular dichroism spectroscopy (41).

The data in Tables 1 and $\mathrm{S} 1$ predict that the $\beta$-strands of FomA consist of maximally $190 \pm 20$ and minimally 170 \pm 24 residues in total. In the three crystal structures of the E. coli outer membrane protein OmpG, which is a 14stranded monomeric $\beta$-barrel $(42,43)$ (PDB entries 2iww, $2 \mathrm{ivw}$, and $2 \mathrm{f} 1 \mathrm{c})$, the total number of residues in the $\beta$-barrel is $178 \pm 6$, corresponding to $13 \pm 2$ residues per strand on average. Note that, in the latter case, the $\beta$-barrel makes up $66-71 \%$ of the entire protein. Thus, in spite of the larger overall protein size, the total $\beta$-sheet content of FomA is close to that of the 14 -stranded $\beta$-barrel of OmpG. This therefore favors a 14-stranded barrel structure also for FomA, although a 16-stranded barrel of $204 \pm 10$ residues cannot be excluded entirely on the basis of the mean number of residues per strand.

$\beta$-Strand Orientation and Configuration. Measurements from the amide infrared dichroism yield a consistent value of $\beta=44.8 \pm 0.5^{\circ}$ for the tilt of the $\beta$-strands of FomA in the different phosphatidylcholine lipid hosts. For a $\beta$-barrel with $n_{\beta}$ strands, the tilt depends on the shear number, $S$, of the barrel according to the following relation $(44,45)$ :

$$
\tan \beta=\frac{h}{D_{\beta}} \frac{\sin \left(\pi / n_{\beta}\right)}{\pi} S
$$

where $h$ is the rise per residue along the strand and $D_{\beta}$ is the separation between strands $\left[h / D_{\beta}=0.719 \pm 0.022(46)\right]$. Definitions of the geometrical parameters and shear number are given in Figure 7. Estimates of the number of strands directly from eq 6 are inherently unstable because they depend very sensitively on the exact value of $h / D_{\beta}$. Using the known values of $n_{\beta, \mathrm{O}}=14$ and $S_{\mathrm{O}}=18$ for OmpG (42) and combining the experimental determinations of $\beta$ for the two proteins according to eq 6 circumvents this problem:

$$
\frac{\tan \beta}{\tan \beta_{\mathrm{O}}}=\frac{\sin \left(\pi / n_{\beta}\right)}{\sin \left(\pi / n_{\beta, \mathrm{O}}\right)}\left(\frac{S}{S_{\mathrm{O}}}\right)
$$

where $\beta_{\mathrm{O}}$ is the strand tilt for OmpG. Assuming that the shear number of FomA is $S=n_{\beta}+4$ (as for OmpG) because this corresponds to the energetically stable configuration for an unstrained barrel $(45,46)$ leads to a prediction of $n_{\beta} \sim 12 \pm$ 2 for FomA. This favors the lower value proposed for the number of $\beta$-barrel strands, viz., $n_{\beta}=14$ (see ref 8 ).

Estimates of the $\beta$-sheet twist, $\theta$, and strand coiling, $\varepsilon$ (see Figure 7, right), can be made from the measured value of $\beta$ for FomA, by using expressions derived for idealized barrels $(17,46)$. If a $\beta$-barrel of 14 strands is assumed, then $\theta=10^{\circ}$ and $\varepsilon=6^{\circ}$ are predicted from the IR dichroism of FomA, whereas $\theta=8^{\circ}$ and $\varepsilon=5^{\circ}$ are predicted if 16 strands are assumed. The corresponding theoretical values for unstrained idealized barrels of 14 (16) strands, where the shear number is $S=n_{\beta}+4$, are as follows: $\theta=10.0^{\circ}\left(8.7^{\circ}\right)$ and $\varepsilon=5.8^{\circ}\left(5.1^{\circ}\right)(45,46)$.
Hydrophobic Matching and Membrane Fluctuations. The square symbols in the top panel of Figure 3 show the dependence of the $\beta$-barrel order parameter, $\left\langle P_{2}(\cos \alpha)\right\rangle$, on lipid chain length, $n_{\mathrm{C}}$, that is obtained from the IR dichroism of FomA in fluid-phase phosphatidylcholine membranes. The order parameter is similar for chain lengths of $C(12: 0)$ and $\mathrm{C}(13: 0)$ but increases steeply beyond this. In common with monomeric $\beta$-barrel outer membrane proteins studied previously, this suggests that the hydrophobic span of FomA corresponds to that of $\mathrm{diC}(13: 0)$ PtdCho bilayers in the fluid phase (cf. refs 17 and 18). From recently refined X-ray data for saturated phosphatidylcholines $(47,48)$, the hydrocarbon thickness of $\operatorname{diC}(13: 0)$ PtdCho bilayers at $30{ }^{\circ} \mathrm{C}$ is estimated to be $d_{\mathrm{c}}=2.3 \mathrm{~nm}(11,49)$. With a mean strand tilt $(\beta)$ of $45^{\circ}$ from IR dichroism, this corresponds to 9.4 residues, on average, in the hydrophobic span of FomA. This corresponds to $70-80 \%$ of the total number of $\beta$-strand residues in FomA, depending on the number of strands (14 or 16, respectively).

The sharp increase in orientational order of FomA in lipids beyond $n_{\mathrm{c}}=13$, which is found also with OmpA and FhuA (17), may be attributed in part to elastic bending fluctuations of the membrane, which modulate the orientation of the protein relative to the ATR substrate (50). The solid line in Figure 3 (top) represents a nonlinear, least-squares fit to the FomA order parameters with a chain length dependence that is predicted for such elastic bending fluctuations (50). This can describe the chain length dependence for $n_{\mathrm{C}} \geq n_{\mathrm{P}}$ reasonably well but requires an appreciable degree of additional static or dynamic disorder parametrized by $f \sim$ 0.5 (see later).

Stoichiometry of Lipid Interaction. It is expected that the lipid stoichiometry of FomA is related to the size (i.e., number of strands) of the $\beta$-barrel and will be reduced if oligomers are formed. The number of lipids that can be accommodated at one intramembranous surface of a $\beta$-sheet (or a large or flattened $\beta$-barrel) with $n_{\beta}$ strands is (51)

$$
N_{\mathrm{b}}=n_{\beta} D_{\beta} /\left(d_{\mathrm{ch}} \cos \beta\right)
$$

where $D_{\beta}(=0.47 \mathrm{~nm})$ is the separation between adjacent strands (see Figure 7) and $d_{\mathrm{ch}}(=0.48 \mathrm{~nm})$ is the width of a lipid chain. Even values of $n_{\beta}$ are required for the all nearestneighbor, antiparallel $\beta$-barrels of outer membrane proteins (see, e.g., refs 46 and 52). With a strand tilt $\beta$ of $44.8 \pm$ $0.5^{\circ}$ from IR dichroism and a stoichiometry $N_{\mathrm{b}}$ of $23 \pm 1$ from spin-label EPR, eq 8 is consistent with a $\beta$-sheet of $n_{\beta}$ $\sim 16.7 \pm 0.7$ strands. For comparison, OmpG, which is known to be monomeric and to have $14 \beta$-strands $(42,43)$, has a lipid stoichiometry $N_{\mathrm{b}}$ of $19.6 \pm 1.0$ and a strand tilt $\beta$ of $44.0 \pm 0.7^{\circ}(18)$. Scaling according to eq 8 would then predict $n_{\beta} \sim 16.2 \pm 1.9$ for FomA, which centers on the absolute prediction of $n_{\beta} \sim 16$, but also embraces the value $n_{\beta} \sim 14$.

These estimates tacitly assume that FomA is monomeric in the membrane. In the trimeric porins such as OmpF and PhoE, ca. $35 \%$ of the $\beta$-strands of each barrel are inaccessible to lipids because they are situated at the trimer interface (53). Thus, if FomA formed such trimers, the total number of $\beta$-strands per barrel would be 1.5 times the number that are exposed to lipids, i.e., 24 strands per monomer. Such a large number of $\beta$-strands is clearly incompatible with the size of FomA and its primary sequence (9). Thus, it must be concluded that FomA does not form trimers in lipid 

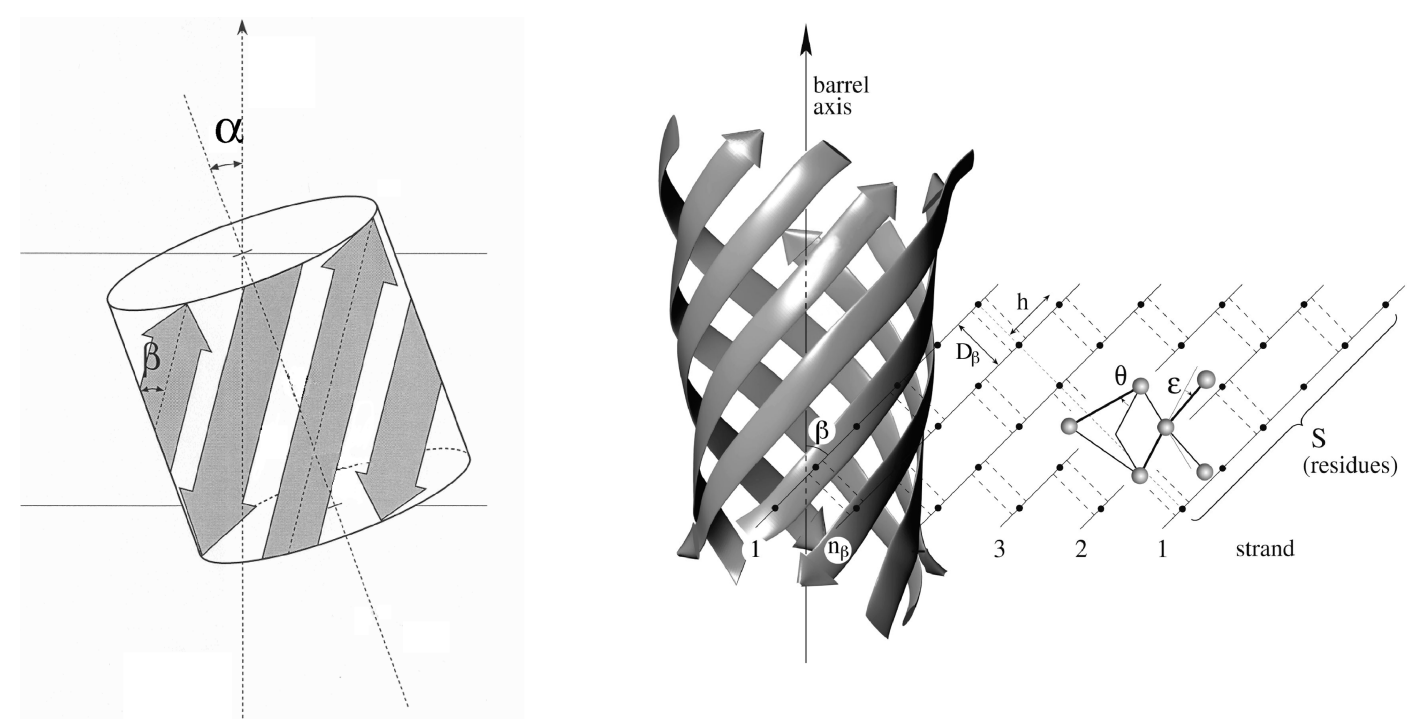

FIgURE 7: Left: Orientation of the $\beta$-strands in a $\beta$-barrel protein. The axis of the $\beta$-barrel is tilted at an angle $\alpha$ to the membrane normal, and the $\beta$-strands are tilted by an angle $\beta$ within the $\beta$-sheets. Right: Topology plot for an antiparallel $\beta$-barrel with $n_{\beta}$ strands. The last strand $\left(n_{\beta}\right)$ is hydrogen-bonded to the first strand (1). The dotted line traces the residue offset that defines the shear number of the barrel, $S$. The local sheet twist, $\theta$, about an axis perpendicular to the strand direction and the local coiling, $\varepsilon$, along the strands are defined by the (exaggerated) displacement of the residues (gray circles) relative to the ideal positions for a planar sheet (black dots).

membranes, consistent with the migration of the nondenatured protein as a compact monomer in SDS-PAGE (10). The trimeric species identified via SDS-PAGE by crosslinking that are reported in ref 4 are not present to any appreciable extent for FomA reconstituted in membranes of diC(14:0)PtdCho. Note also that the FomA species that inserts and folds as a monomer in phosphatidylcholine membranes forms functional channels of unimodal conductance in black lipid membranes (10).

Selectivity of Lipid-Protein Interaction. FomA displays a pronounced selectivity for interaction with the negatively charged lipids phosphatidylserine and stearic acid (see Table 2); the selectivity for phosphatidic acid is only marginal, and in common with many integral proteins (see, e.g., refs 33 and 54-57), little selectivity is found for phosphatidylglycerol. Previous studies have revealed only very limited selectivity in interaction of spin-labeled lipids with the outer membrane proteins OmpA (16) and OmpG (18), whereas a pronounced selectivity for anionic lipids was found with FhuA (16). This difference was attributed to the electrostatic potentials of these proteins in the vicinity of the membrane polar-apolar interface. FhuA is characterized by a strongly basic patch on the extracellular side which OmpA has relatively few charged residues in the interfacial regions, and OmpG has a preponderance of acidic residues.

Relative to OmpG and OmpA, the FomA outer membrane protein is rich in basic amino acid residues. In the 14-stranded (and in the 16-stranded) topology model, many of these positively charged side chains are predicted to lie close to the lipid headgroups, both on the external side and on the periplasmic side of the membrane $(8,9)$. Thus, the selectivity of FomA for anionic lipids that is observed here gives support for the overall transmembrane topography of the $\beta$-strands that is proposed from the amino acid sequence. Interestingly, an asymmetric distribution of positive and negative charges was invoked recently to explain the $\mathrm{pH}$ dependence of the binding of Skp to FomA (58). In this case, the Skp protein is basic and its binding to charged-segregated regions of acidic residues on FomA is complementary to the binding of anionic lipid headgroups to basic side chains, which are enriched at the membrane-water interface.

The pattern of selectivity of FomA for negatively charged lipids reveals that this is not solely of a simple Coulombic origin. This is the case for the anionic lipid selectivity displayed by integral proteins in general. Selectivities for lipids with the same formal charge are not always identical, and removal of lipid headgroup charge by $\mathrm{pH}$ titration or screening of electrostatics at high ionic strengths does not lead inevitably to removal of the selectivity for negatively charged lipids $(30,39)$. The most likely reason for differences in selectivity between negatively charged lipids lies in different hydration states of the various lipid headgroups and polar amino acid side chains (cf. refs 59-61). Anomalously high selectivities for stearic acid may also be related to the ability of fatty acids to shift vertical location in the membrane depending on protonation state $(62,63)$.

Comparison with Other Outer Membrane Proteins. It is useful to compare the present results with those from similar measurements on monomeric $\beta$-barrel membrane proteins, the structure of which is known (16-18). Figure 8 shows the dependence of different parameters on the number of strands, $n_{\beta}$, in the $\beta$-barrel, for OmpA $\left(n_{\beta}=8 ; S=10\right)$, OmpG $\left(n_{\beta}=14 ; S=18\right)$, and FhuA $\left(n_{\beta}=22 ; S=24\right)$. Corresponding data from FomA are given by solid horizontal lines in Figure 8. As noted already, the stoichiometry of motionally restricted lipids for FomA is compatible with an $n_{\beta}$ of 16 , whereas the value of the strand tilt favors $n_{\beta}$ values of $\leq 14$. The order parameter of FomA in the fluid phase of $\operatorname{diC}(17: 0)$ PtdCho membranes is lower even than that of OmpA at the same temperature. Whereas this corresponds to the trend expected for a 14-stranded barrel relative to one with 16 strands, the low value suggests a qualitative difference from the reference proteins. Note that this is a feature in common with FomA in fluid lipid hosts of all chain lengths that were tested (cf. Figure 3, top). Possible reasons for the difference are that sections of $\beta$-strand extending beyond the transmembrane barrel region are less ordered in FomA than in the other proteins and that the low ionic 


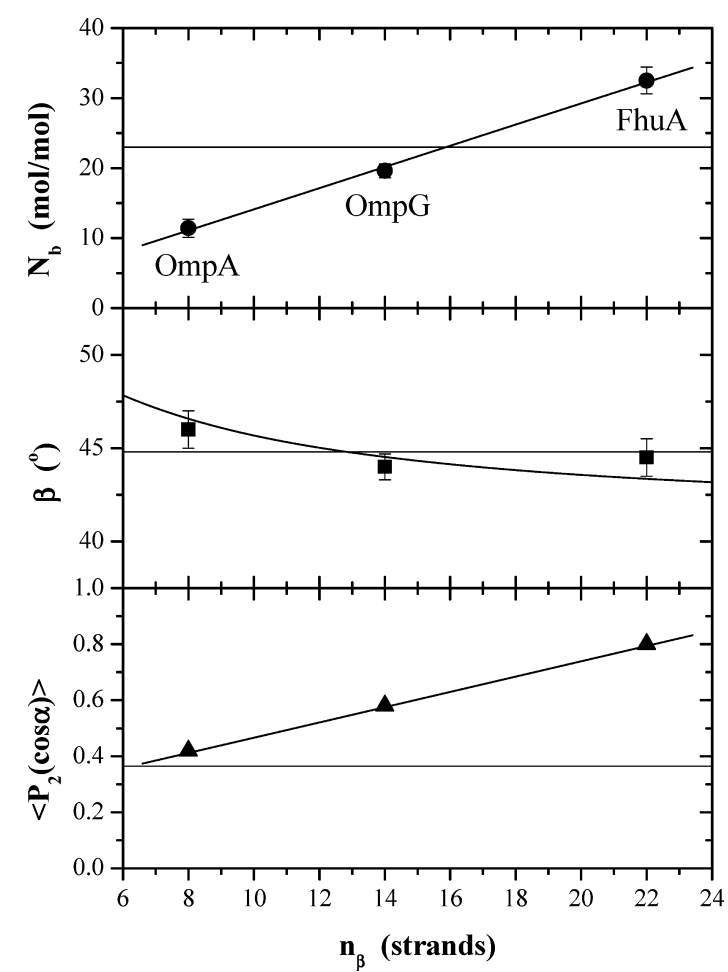

FIGURE 8: Dependence on the number of $\beta$-strands, $n_{\beta}$, of (top panel, O) the motionally restricted lipid stoichiometry, $N_{\mathrm{b}}$; (center panel, 口) $\beta$-strand tilt, $\beta$; and (bottom panel, $\boldsymbol{\Delta}$ ) $\beta$-barrel order parameter, $\left\langle P_{2}(\cos \alpha)\right\rangle$, in fluid-phase $\operatorname{diC}(17: 0)$ PtdCho, for the monomeric $E$. coli outer membrane proteins OmpA, OmpG, and FhuA (16-18). Horizontal lines indicate the corresponding values for FomA. Straight sloping lines are linear regressions.

strength (no $\mathrm{NaCl}$ ) that is necessary for successful reconstitution of FomA results in membranes that are less well aligned in the fluid phase than those in buffers containing higher concentrations of salt $(250 \mathrm{mM} \mathrm{NaCl})$ (cf. refs 17 and 18$)$.

The comparisons given in Figure 8, and others discussed above, indicate that FomA is a monomeric $\beta$-barrel in phosphatidylcholine membranes, as suggested by more recent results on the behavior of nondenatured samples in SDS-PAGE (10). On balance, the present data also favor the more recently published 14-stranded topology model (8), although only 150 residues are explicitly designated as $\beta$-sheet in the latter, which is at the lower limit of the minimal estimate from the present IR measurements.

\section{ACKNOWLEDGMENT}

We thank Frau B. Angerstein for synthesis of spin-labeled phospholipids.

\section{SUPPORTING INFORMATION AVAILABLE}

Band fitting of the polarized ATR spectra from the amide I band of FomA (Table S1), order parameters, $\left\langle P_{2}(\cos \alpha)\right\rangle$, and mean effective inclinations, $\alpha$, of the $\beta$-sheets of FomA (Table S2), effective tilt angles, $\theta_{\mathrm{ch}}$, of lipid chains in aligned membranes of disaturated phosphatidylcholines containing FomA (Table S3), temperature dependence of the central line height in the EPR spectra of the 14-PCSL spin-label in $\operatorname{diC}(14: 0)$ PtdCho membranes containing FomA (Figure S1), and spectral subtractions to quantitate the relative proportions of the fluid (fraction, $1-f_{\mathrm{b}}$ ) and motionally restricted (fraction, $f_{\mathrm{b}}$ ) components from the EPR spectra of 14-PCSL in FomA/diC(14:0)PtdCho membranes (Figure S2). This material is available free of charge via the Internet at http:// pubs.acs.org.

\section{REFERENCES}

1. Kornman, K. S., Holt, S. C., and Robertson, P. B. (1981) The microbiology of ligature-induced periodontitis in the cynomolgus monkey. J. Periodontal Res. 16, 363-371.

2. Moore, W. E. C., and Moore, L. V. H. (1994) The bacteria of periodontal diseases. Periodontology 2000 5, 66-77.

3. Kolenbrander, P. E., and London, J. (1993) Adhere today, here tomorrow: Oral bacterial adherence. J. Bacteriol. 175, 3247-3252.

4. Kleivdal, H., Benz, R., and Jensen, H. B. (1995) The Fusobacterium nucleatum major outer-membrane protein (FomA) forms trimeric, water-filled channels in lipid bilayer membranes. Eur. J. Biochem. 233, 310-316.

5. Kaufman, U., and DiRienzo, J. M. (1989) Isolation of a corncob (coaggregation) receptor polypeptide from Fusobacterium nucleatum. Infect. Immun. 57, 331-337.

6. Kinder, S. A., and Holt, S. C. (1993) Localization of the Fusobacterium nucleatum T18 adhesin activity mediating coaggregation with Porphyromonas gingivalis T22. J. Bacteriol. 175, 840-850.

7. Bolstad, A. I., and Jensen, H. B. (1993) Complete sequence of omp 1 , the structural gene encoding the $40-\mathrm{kDa}$ outer membrane protein of Fusobacterium nucleatum strain Fev1. Gene 132, 107112.

8. Puntervoll, P., Ruud, M., Bruseth, L. J., Kleivdal, H., Høgh, B. T., Benz, R., and Jensen, H. B. (2002) Structural characterization of the fusobacterial non-specific porin FomA suggests a 14-stranded topology, unlike the classical porins. Microbiology 148, 3395-3403.

9. Bolstad, A. I., Tommassen, J., and Jensen, H. B. (1994) Sequence variability of the $40-\mathrm{kDa}$ outer membrane proteins of Fusobacterium nucleatum strains and a model for the topology of the proteins. Mol. Gen. Genet. 244, 104-110.

10. Pocanschi, C. L., Apell, H. J., Puntervoll, P., Hogh, B., Jensen, H. B., Welte, W., and Kleinschmidt, J. H. (2006) The major outer membrane protein of Fusobacterium nucleatum (FomA) folds and inserts into lipid bilayers via parallel folding pathways. J. Mol. Biol. 355, 548-561.

11. Marsh, D. (2008) Energetics of hydrophobic matching in lipidprotein interactions. Biophys. J. 94, 3996-4013.

12. Marsh, D. (1997) Dichroic ratios in polarized Fourier transform infrared for nonaxial symmetry of $\beta$-sheet structures. Biophys. $J$. $72,2710-2718$.

13. Marsh, D. (1999) Spin label ESR spectroscopy and FTIR spectroscopy for structural/dynamic measurements on ion channels. Methods Enzymol. 294, 59-92.

14. Marsh, D., and Horváth, L. I. (1998) Structure, dynamics and composition of the lipid-protein interface. Perspectives from spinlabelling. Biochim. Biophys. Acta 1376, 267-296.

15. Marsh, D. (2008) New methods in membrane protein research. Electron spin resonance in membrane research: Protein-lipid interactions. Methods XXX-XXX. (in press).

16. Ramakrishnan, M., Pocanschi, C. L., Kleinschmidt, J. H., and Marsh, D. (2004) Association of spin-labelled lipids with $\beta$-barrel proteins from the outer membrane of Escherichia coli. Biochemistry 43, 11630-11636.

17. Ramakrishnan, M., Qu, J., Pocanschi, C. L., Kleinschmidt, J. H., and Marsh, D. (2005) Orientation of $\beta$-barrel proteins OmpA and FhuA in lipid membranes. Chainlength dependence from infrared dichroism. Biochemistry 44, 3515-3523.

18. Anbazhagan, V., Qu, J., Kleinschmidt, J. H., and Marsh, D. (2008) Incorporation of outer membrane protein OmpG in lipid membranes. Protein-lipid interactions and $\beta$-barrel orientation. Biochemistry 47, 6189-6198.

19. Hubbell, W. L., and McConnell, H. M. (1971) Molecular motion in spin-labelled phospholipids and membranes. J. Am. Chem. Soc. 93, 314-326.

20. Marsh, D., and Watts, A. (1982) Spin-labeling and lipid-protein interactions in membranes. In Lipid-Protein Interactions (Jost, P. C., and Griffith, O. H., Eds.) Vol. 2, pp 53-126, WileyInterscience, New York.

21. Schorn, K., and Marsh, D. (1996) Lipid chain dynamics and molecular location of diacylglycerol in hydrated binary mixtures with phosphatidylcholine: Spin label ESR studies. Biochemistry 35, 3831-3836. 
22. Lowry, O. H., Rosebrough, N. J., Farr, L., and Randall, R. J. (1951) Protein measurement with the Folin phenol reagent. J. Biol. Chem. 193, 265-275.

23. Kóta, Z., Páli, T., and Marsh, D. (2004) Orientation and lipidpeptide interactions of gramicidin A in lipid membranes: Polarized ATR infrared spectroscopy and spin-label electron spin resonance. Biophys. J. 86, 1521-1531.

24. Marsh, D. (1982) Electron spin resonance: Spin label probes. In Techniques in Lipid and Membrane Biochemistry (Metcalfe, J. C., and Hesketh, T. R., Eds.) Vol. B4/II, pp B426-1-B426-44, Elsevier, Amsterdam.

25. Miyazawa, T. (1960) Perturbation treatment of the characteristic vibrations of polypeptide chains in various configurations. J. Chem. Phys. 32, 1647-1652.

26. Marsh, D. (1990) Handbook of Lipid Bilayers, CRC Press, Boca Raton, FL.

27. Marsh, D. (1983) Spin label answers to lipid-protein interactions. Trends Biochem. Sci. 8, 330-333.

28. Pates, R. D., and Marsh, D. (1987) Lipid mobility and order in bovine rod outer segment disk membranes. A spin-label study of lipid-protein interactions. Biochemistry 26, 29-39.

29. Watts, A., Davoust, J., Marsh, D., and Devaux, P. F. (1981) Distinct states of lipid mobility in bovine rod outer segment membranes. Resolution of spin label results. Biochim. Biophys. Acta 643, 673676.

30. Esmann, M., and Marsh, D. (1985) Spin-label studies on the origin of the specificity of lipid-protein interactions in $\mathrm{Na}^{+}, \mathrm{K}^{+}$-ATPase membranes from Squalus acanthias. Biochemistry 24, 3572-3578.

31. Marsh, D. (2008) Protein modulation of lipids, and vice-versa, in membranes. Biochim. Biophys. Acta 1778, 1545-1575.

32. Brotherus, J. R., Griffith, O. H., Brotherus, M. O., Jost, P. C., Silvius, J. R., and Hokin, L. E. (1981) Lipid-protein multiple binding equilibria in membranes. Biochemistry 20, 5261-5267.

33. Knowles, P. F., Watts, A., and Marsh, D. (1979) Spin label studies of lipid immobilization in dimyristoylphosphatidylcholine-substituted cytochrome oxidase. Biochemistry 18, 4480-4487.

34. Brophy, P. J., Horváth, L. I., and Marsh, D. (1984) Stoichiometry and specificity of lipid-protein interaction with myelin proteolipid protein studied by spin-label electron spin resonance. Biochemistry 23, 860-865.

35. Peelen, S. J. C. J., Sanders, J. C., Hemminga, M. A., and Marsh, D. (1992) Stoichiometry, selectivity, and exchange dynamics of lipid-protein interaction with bacteriophage M13 coat protein studied by spin label electron spin resonance. Effects of protein secondary structure. Biochemistry 31, 2670-2677.

36. Horváth, L. I., Drees, M., Beyer, K., Klingenberg, M., and Marsh, D. (1990) Lipid-protein interactions in ADP-ATP carrier/egg phosphatidylcholine recombinants studied by spin-label ESR spectroscopy. Biochemistry 29, 10664-10669.

37. Esmann, M., Watts, A., and Marsh, D. (1985) Spin-label studies of lipid-protein interactions in $\left(\mathrm{Na}^{+}, \mathrm{K}^{+}\right)$-ATPase membranes from rectal glands of Squalus acanthias. Biochemistry 24, 1386-1393.

38. Powell, G. L., Knowles, P. F., and Marsh, D. (1987) Spin label studies on the specificity of interaction of cardiolipin with beef heart cytochrome oxidase. Biochemistry 26, 8138-8145.

39. Horváth, L. I., Brophy, P. J., and Marsh, D. (1988) Influence of lipid headgroup on the specificity and exchange dynamics in lipidprotein interactions. A spin label study of myelin proteolipid apoprotein-phospholipid complexes. Biochemistry 27, 5296-5304.

40. Goormaghtigh, E., Cabiaux, V., and Ruysschaert, J.-M. (1994) Determination of soluble and membrane protein structure by Fourier transform infrared spectroscopy. III. Secondary structures. Subcell. Biochem. 23, 405-450.

41. Greenfield, N. J. (1996) Methods to estimate the conformation of proteins and polypeptides from circular dichroism data. Anal. Biochem. 235, 1-10.

42. Subbarao, G. V., and van den Berg, B. (2006) Crystal structure of the monomeric porin OmpG. J. Mol. Biol. 360, 750-759.

43. Yildiz, Ö., Vinothkumar, K. R., Goswami, P., and Kühlbrandt, W. (2006) Structure of the monomeric outer-membrane porin OmpG in the open and closed conformation. EMBO J. 25, 3702-3713.
44. Chou, K.-C., Carlacci, L., and Maggiora, G. G. (1990) Conformational and geometrical properties of idealized $\beta$-barrels in proteins. J. Mol. Biol. 213, 315-326.

45. Marsh, D. (2000) Infrared dichroism of twisted $\beta$-sheet barrels. The structure of E. coli outer membrane proteins. J. Mol. Biol. 297, 803-808.

46. Páli, T., and Marsh, D. (2001) Tilt, twist and coiling in $\beta$-barrel membrane proteins: Relation to infrared dichroism. Biophys. J. 80, 2789-2797.

47. Kučerka, N., Liu, Y., Chu, N., Petrache, H. I., Tristram-Nagle, S., and Nagle, J. F. (2005) Structure of fully hydrated fluid phase DMPC and DLPC lipid bilayers using X-ray scattering from oriented multilamellar arrays and from unilamellar vesicles. Biophys. J. 88, 2626-2637.

48. Kučerka, N., Tristram-Nagle, S., and Nagle, J. F. (2006) Closer look at structure of fully hydrated fluid phase DPPC bilayers. Biophys. J. 90, L83-L85.

49. Marsh, D., Jost, M., Peggion, C., and Toniolo, C. (2007) Lipid chainlength dependence for incorporation of alamethicin in membranes: EPR studies on TOAC-spin labelled analogues. Biophys. J. 92, 4002-4011.

50. Marsh, D., Shanmugavadivu, B., and Kleinschmidt, J. H. (2006) Membrane elastic fluctuations and the insertion and tilt of $\beta$-barrel proteins. Biophys. J. 91, 227-232.

51. Marsh, D. (1997) Stoichiometry of lipid-protein interaction and integral membrane protein structure. Eur. Biophys. J. 26, 203208.

52. Schulz, G. E. (2002) The structure of bacterial outer membrane proteins. Biochim. Biophys. Acta 1565, 308-317.

53. Cowan, S. W., Schirmer, T., Rummel, G., Steiert, M., Ghosh, R., Pauptit, R. A., Jansonius, J. N., and Rosenbusch, J. P. (1992) Crystal structures explain functional properties of two $E$. coli porins. Nature 358, 727-733.

54. Horváth, L. I., Brophy, P. J., and Marsh, D. (1990) Influence of polar residue deletions on lipid-protein interactions with the myelin proteolipid protein. Spin-label ESR studies with DM-20/lipid recombinants. Biochemistry 29, 2635-2638.

55. Horváth, L. I., Heimburg, T., Kovachev, P., Findlay, J. B. C., Hideg, K., and Marsh, D. (1995) Integration of a $\mathrm{K}^{+}$channel-associated peptide in a lipid bilayer: Conformation, lipid-protein interactions, and rotational diffusion. Biochemistry 34, 3893-3898.

56. Arora, A., Williamson, I. M., Lee, A. G., and Marsh, D. (2003) Lipid-protein interactions with cardiac phospholamban studied by spin-label electron spin resonance. Biochemistry 42, 5151-5158.

57. Hubert, A., Henderson, P. J. F., and Marsh, D. (2003) Lipid-protein interactions in Escherichia coli membranes overexpressing the sugar- $\mathrm{H}^{+}$symporter, GalP. EPR of spin-labelled lipids. Biochim. Biophys. Acta 1611, 243-248.

58. Qu, J., Mayer, C., Behrens, S., Holst, O., and Kleinschmidt, J. H. (2007) The trimeric periplasmic chaperone Skp of Escherichia coli forms 1:1 complexes with outer membrane proteins via hydrophobic and electrostatic interactions. J. Mol. Biol. 374, 91-105.

59. Cevc, G., Watts, A., and Marsh, D. (1980) Non-electrostatic contribution to the titration of the ordered-fluid phase transition of phosphatidylglycerol bilayers. FEBS Lett. 120, 267-270.

60. Cevc, G., Watts, A., and Marsh, D. (1981) Titration of the phase transition of phosphatidylserine bilayer membranes. Effects of $\mathrm{pH}$, surface electrostatics, ion binding and headgroup hydration. Biochemistry 20, 4955-4965.

61. Cevc, G., Seddon, J. M., and Marsh, D. (1985) Thermodynamic and structural properties of phosphatidylserine bilayer membranes in the presence of lithium ions and protons. Biochim. Biophys. Acta $814,141-150$.

62. Rama Krishna, Y. V. S., and Marsh, D. (1990) Spin label ESR and ${ }^{31} \mathrm{P}-\mathrm{NMR}$ studies of the cubic and inverted hexagonal phases of dimyristoylphosphatidylcholine/myristic acid $(1: 2, \mathrm{~mol} / \mathrm{mol})$ mixtures. Biochim. Biophys. Acta 1024, 89-94.

63. Miyazaki, J., Hideg, K., and Marsh, D. (1992) Interfacial ionization and partitioning of membrane-bound local anaesthetics. Biochim. Biophys. Acta 1103, 62-68.

64. Marsh, D. (1999) Quantitation of secondary structure in ATR infrared spectroscopy. Biophys. J. 77, 2630-2637.

BI800750S 